\title{
Miocene Weathering and the Stable Carbon Isotope Geochemistry of Goethite in CID of Western Australia
}

Tyler O. Fritz ${ }^{1}$, Crayton J. Yapp

1. Huffington Department of Earth Sciences, Southern Methodist University, Dallas TX, 75275

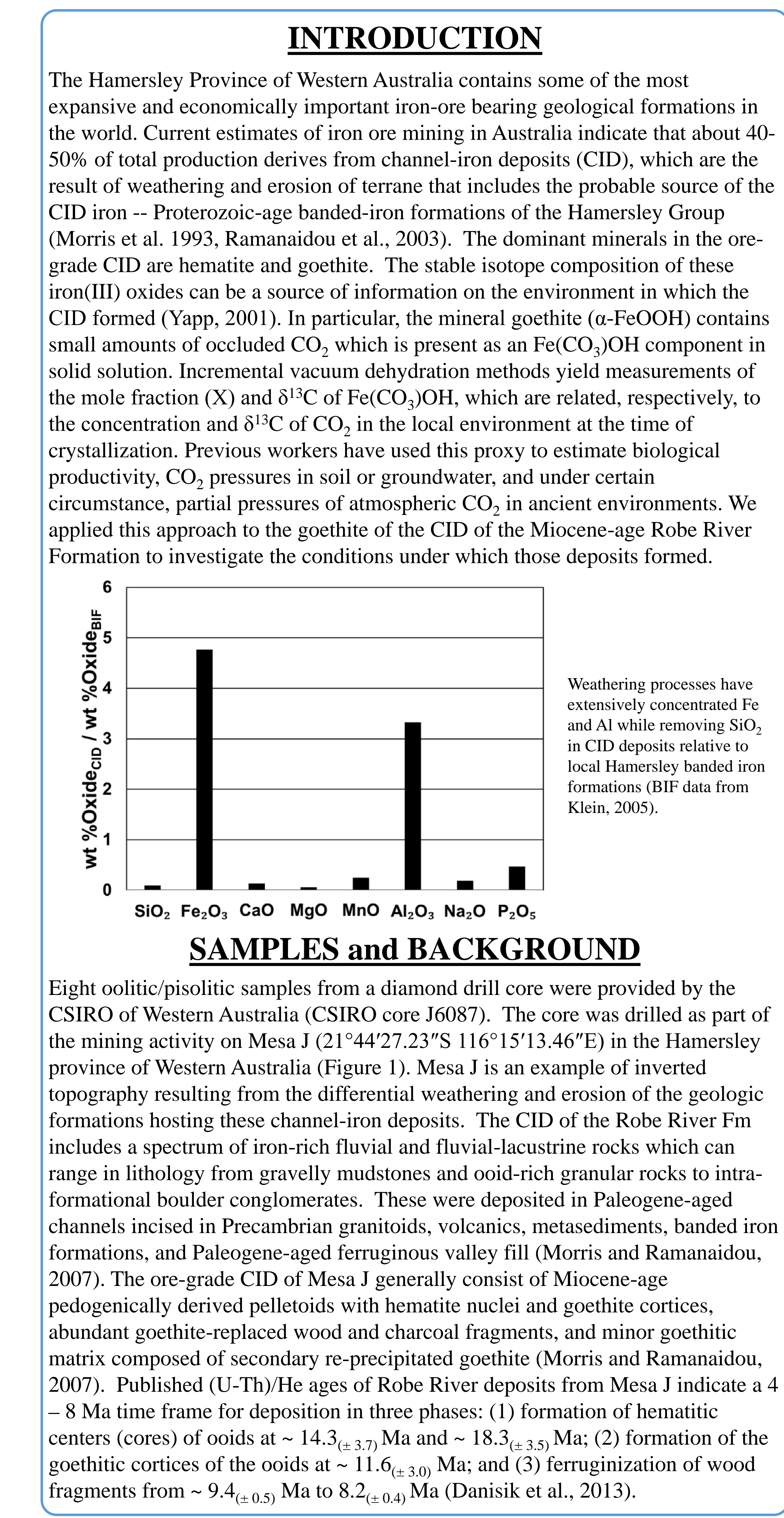

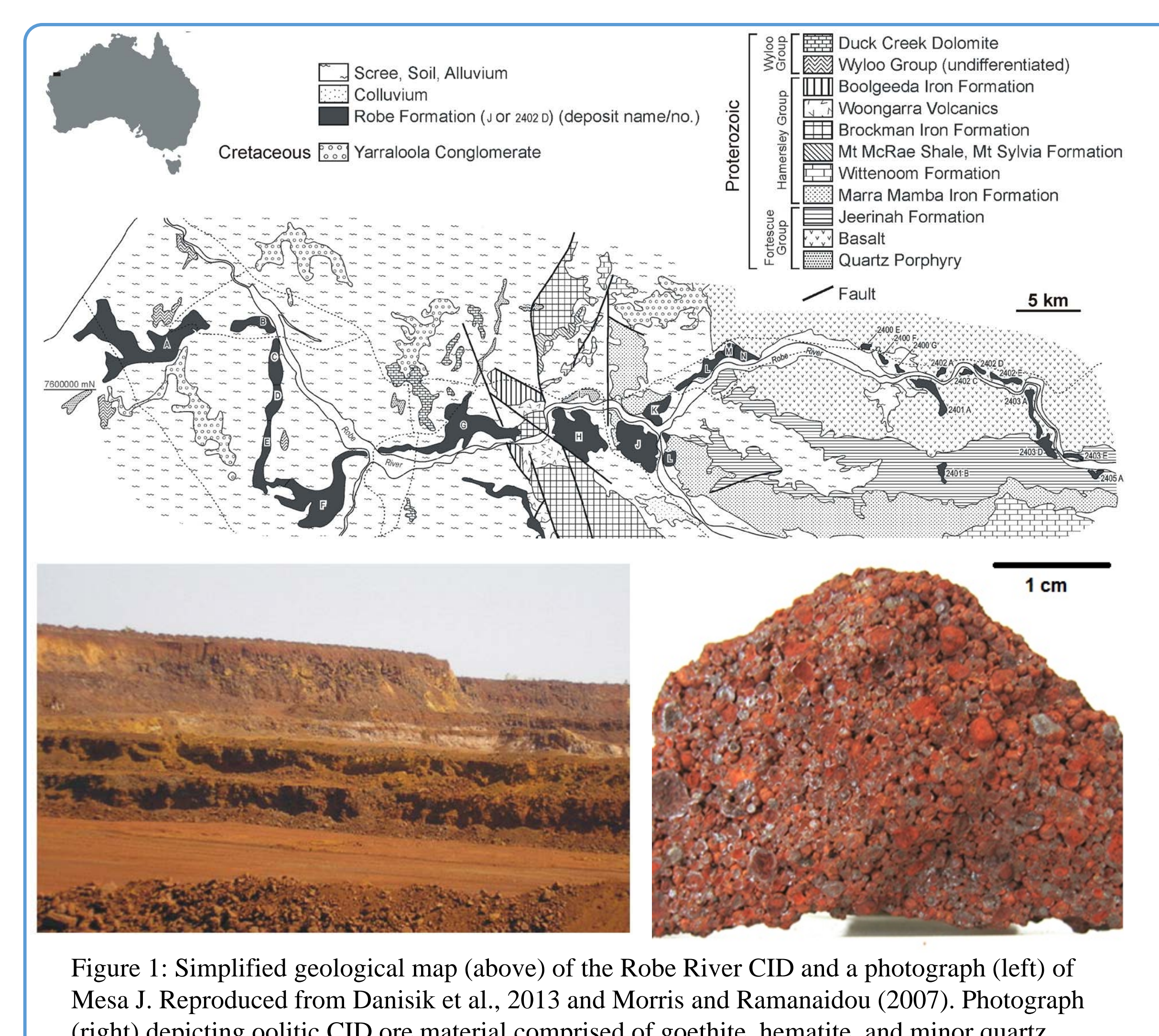

METHODS

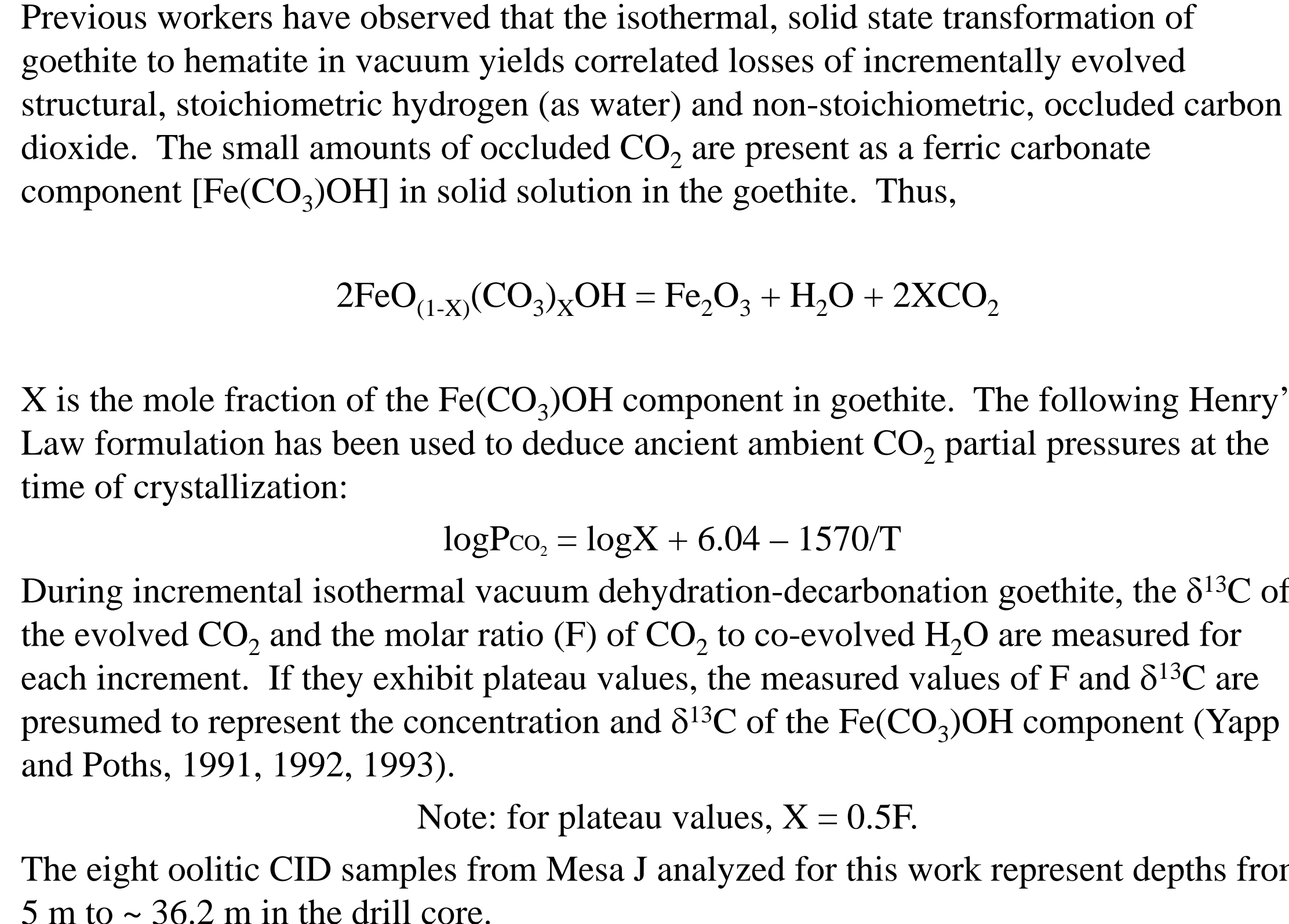

The eight oolitic CID samples for
$5 \mathrm{~m}$ to $~ 36.2 \mathrm{~m}$ in the drill core
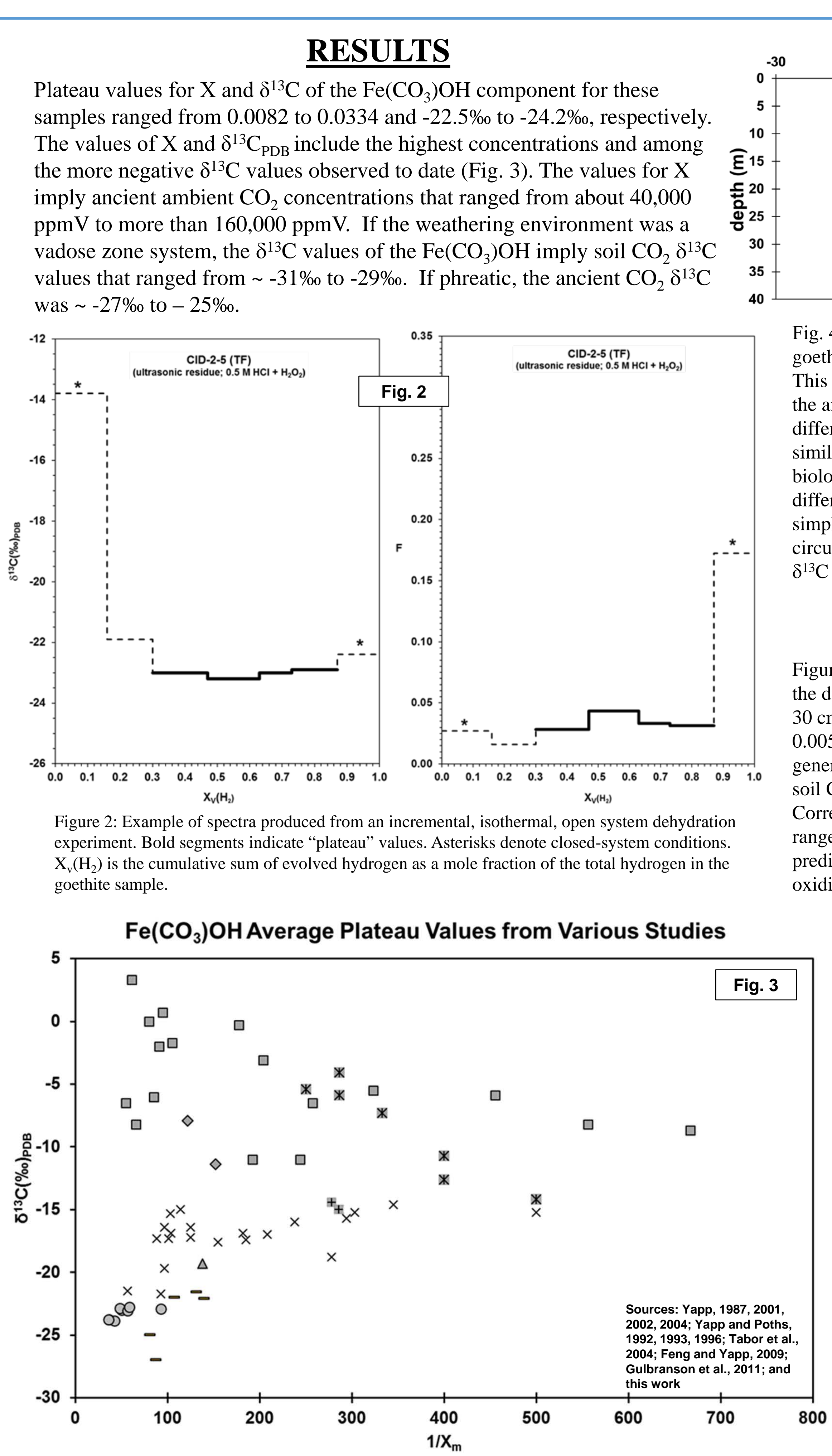

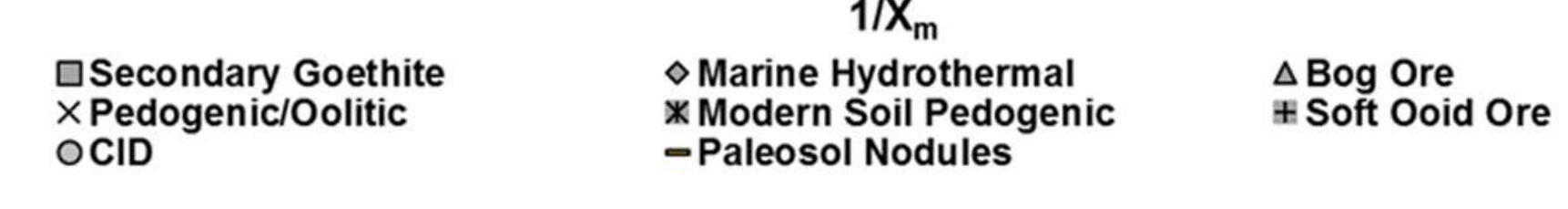

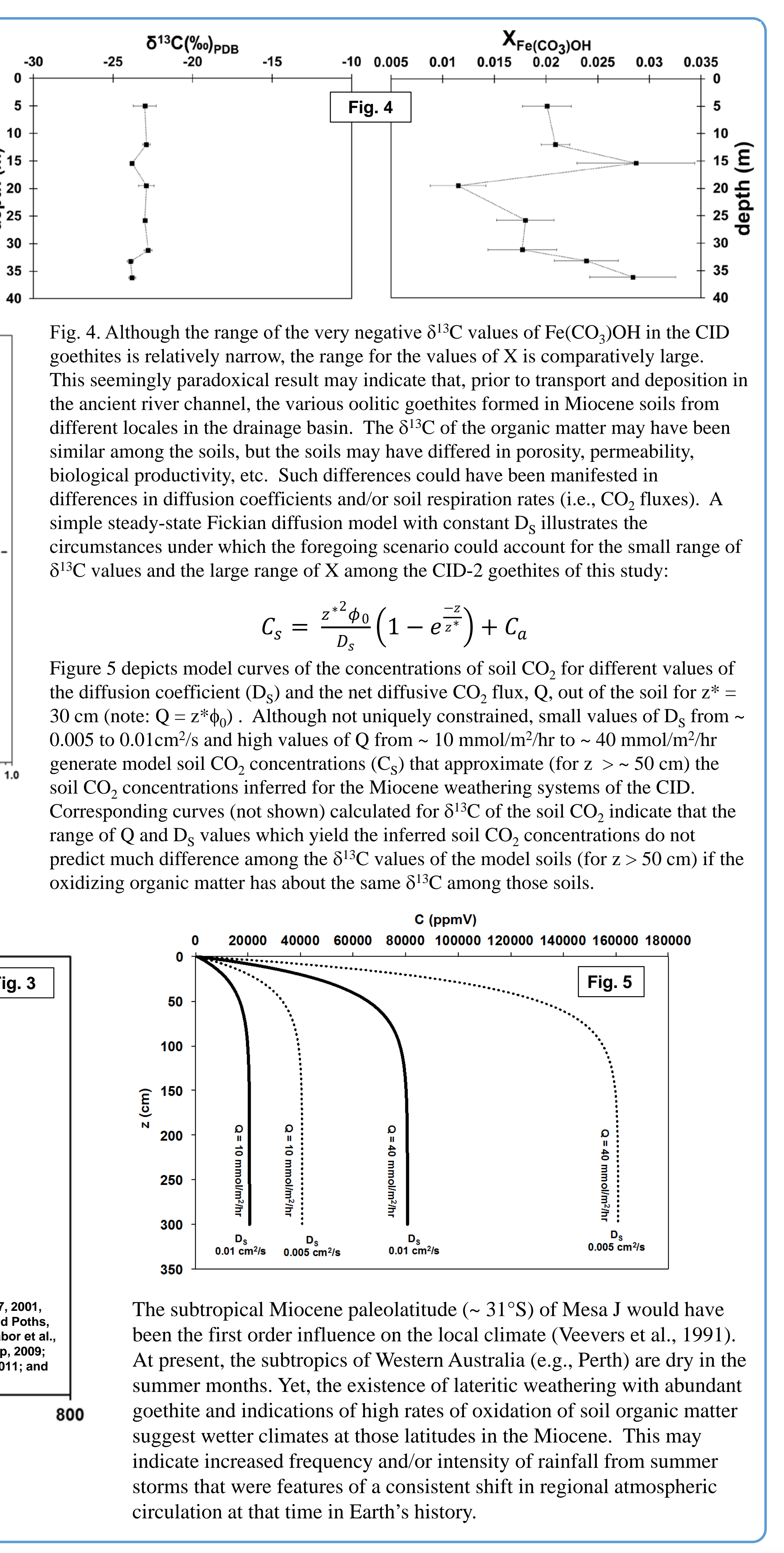

CONCLUSIONS

The high concentrations and very negative $\delta^{13} \mathrm{C}$ values inferred for oxidation of in situ organic matter. Such high rates were probably microbially mediated and if so, could be indicative of widespread
biological activity in the soil systems of the Hamersley province during

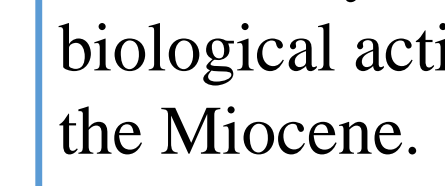

Previous workers have suggested that biological activity may have played
a role in the weathering processes that generated the scale of iron enrichment and accumulation seen in channel-iron deposs tauna might (a) reduction ith oneidensis, which are capable of diss environments, microbial activity can induce local, reductive dissolution of iron (III) oxides at the microbeeminineral interfface (Grantham et al., 1997,
Hersman et al 1996). Upon cessation of that biological activit, the it would re-oxidize and crystallize as iron (III) oxides.

If the two foregoing categories of microbially mediated processes
operated in the Miocene and acted in tandem, one set could have

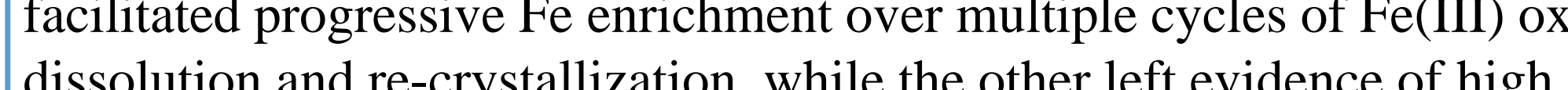
concentrations of soil $\mathrm{CO}_{2}$ with very negative ${ }^{\mathrm{i}} \mathrm{C} \mathrm{C}$ values, However, as indicated by the (U-Th)/He ages, the Fe recycling processes have not be REFERENCES

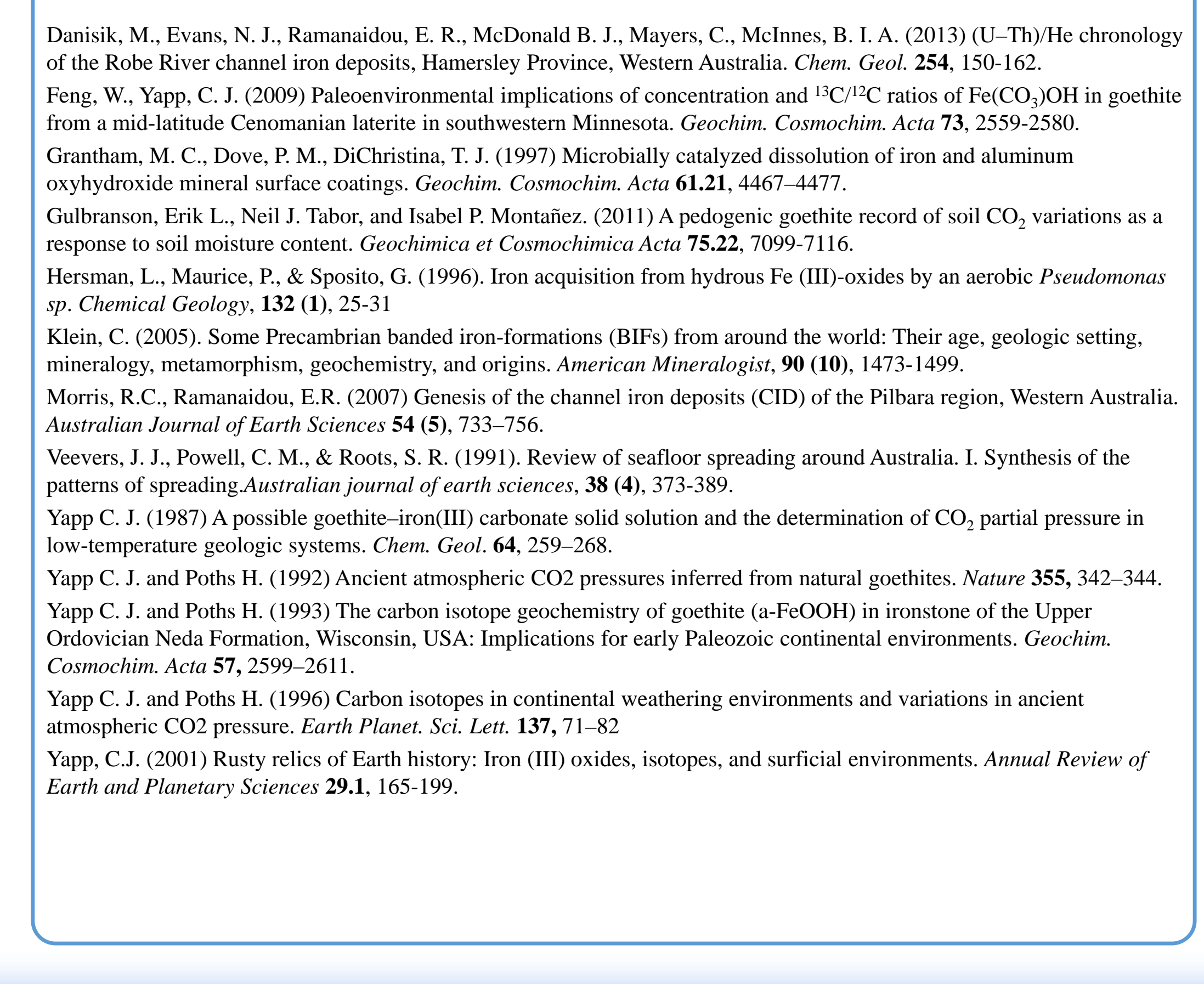

